BMJ Open

Diabetes

Research

\& Care

\section{Lower glycemic load meals reduce diurnal glycemic oscillations in women with risk factors for gestational diabetes}

To cite: Kizirian NV, Goletzke J, Brodie S, et al. Lower glycemic load meals reduce diurnal glycemic oscillations in women with risk factors for gestational diabetes. BMJ Open Diabetes Research and Care 2017;5: e000351. doi:10.1136/bmjdrc2016-000351

Received 27 October 2016 Revised 15 February 2017 Accepted 9 March 2017

CrossMark

For numbered affiliations see end of article.

Correspondence to Professor Jennie C BrandMiller; jennie.brandmiller@ sydney.edu.au

\begin{abstract}
Nathalie V Kizirian, ${ }^{1,2}$ Janina Goletzke, ${ }^{1,2,3}$ Shannon Brodie, ${ }^{1,2,4}$ Fiona S Atkinson, ${ }^{1,2}$ Tania P Markovic, ${ }^{4,5}$ Glynis P Ross, ${ }^{5,6}$ Anette Buyken, ${ }^{3}$ Jennie C Brand-Miller ${ }^{1,2,4}$
\end{abstract}

\section{ABSTRACT}

Objective: Maternal glycemia plays a key role in fetal growth. We hypothesized that lower glycemic load $(G L)$ meals (lower glycemic index, modestly lower carbohydrate) would substantially reduce day-long glucose variability in women at risk of gestational diabetes mellitus (GDM).

Research design and methods: A crossover study of 17 women (mean \pm SD age $34.8 \pm 4$ years; gestational weeks $29.3 \pm 1.3$; body mass index $23.8 \pm 4.7 \mathrm{~kg} / \mathrm{m}^{2}$ ) who consumed a low GL or a high GL diet in random order, 1-day each, over 2 consecutive days. Diets were energy-matched and fiber-matched with 5 meals per 24 hours. All food was provided. Continuous glucose monitoring was used to assess diurnal glycemia.

Results: Maternal glucose levels were $51 \%$ lower on the low GL day with lower incremental area under the curve (iAUC \pm SEM $549 \pm 109$ vs $1120 \pm 198 \mathrm{mmol} / \mathrm{L} \mathrm{min}$, $p=0.015)$. Glycemic variability was significantly lower on the low GL day, as demonstrated by a lower average SD $(0.7 \pm 0.1$ vs $0.9 \pm 0.1, p<0.001)$ and lower mean amplitude of glycemic excursions $(2.1 \pm 0.2$ vs 2.7 $\pm 0.2 \mathrm{mmol} / \mathrm{L}, \mathrm{p}<0.001$ ).

Conclusions: A lower GL meal plan in pregnancy acutely halves day-long maternal glucose levels and reduces glucose variability, providing further evidence to support the utility of a low GL diet in pregnancy.

\section{INTRODUCTION}

Maternal glucose intolerance is an important predictor of adverse perinatal outcomes, ${ }^{1}$ including increased risk of offspring diabetes and obesity in later life. ${ }^{2-4}$ Importantly, the consequences of maternal glycemia on perinatal outcomes do not occur at a specific threshold but rather on a continuum. ${ }^{1}$ Recently, glycemic variability, characterized by acute and chronic glucose excursions, was associated with increased infant ponderal index in women with type 1 diabetes ${ }^{5}$ and impaired early-phase insulin secretion in women with gestational diabetes mellitus (GDM). ${ }^{6}$ Glucose oscillation has been found to induce greater oxidative stress and tissue damage than sustained high blood glucose

\section{Significance of this study}

What is already known about this subject?

Glycemic variability, characterized by acute and chronic glucose excursions, is an important predictor of comorbidities in individuals with diabetes. Low glycemic index (GI) foods produce lower postprandial blood glucose spikes compared to high $\mathrm{Gl}$ foods. In several randomized controlled trials (but not all), low Gl diets in pregnancy have resulted in lower (normalized) birth weight, lower ponderal index improved glucose tolerance, lower gestational weight gain, and reduction in need for insulin therapy in women with gestational diabetes mellitus (GDM).

\section{What are the new findings?}

Low glycemic load meals improve diurnal glucose control and produce less glycemic variability than conventional diets in women at risk of GDM.

How might these results change the focus of research or clinical practice?

Modestly lower carbohydrate diets with an emphasis on low Gl food sources can be recommended to women at risk of developing diabetes in pregnancy.

levels (BGLs) ${ }^{7-9}$ Given the strong associations between maternal glycemia, perinatal outcomes and fetal programming, strategies to optimize maternal glycemic control are crucial for the long-term health of mother and offspring. ${ }^{1} 610$

Blood glucose concentrations are strongly influenced by the quality and quantity of carbohydrates in the diet. In healthy individuals and those with diabetes, low glycemic index (GI) foods produce lower postprandial blood glucose spikes compared to high GI foods ${ }^{11}$ and have been associated with improved diurnal glycemic profiles and lesser glycemic variability, compared to a high GI diet. ${ }^{12-15}$ Dietary glycemic load (GL), the product of the GI of a food and its carbohydrate content, has been found to be the best predictor of postprandial glycemia and insulinemia in healthy adults consuming a mixed diet. ${ }^{16}$ Thus, the 
combination of a modestly lower carbohydrate intake from low GI food sources with a reciprocal increase in fat and protein may be the simplest dietary strategy to optimize maternal glucose control.

Until now, no study has explored the effect of diets of varying dietary GL on diurnal glucose levels and glycemic variability in pregnancy. The aim of this study was to use continuous glucose monitoring (CGM) to test the acute effect of two fiber-matched diets, one high GL and one low GL, 1-day each, on glycemic profiles and glycemic variability in third trimester pregnant women at risk of GDM. We hypothesized that the low GL meals would produce lower diurnal glucose levels and lesser glycemic variability, compared to the high GL meals.

\section{RESEARCH DESIGN AND METHODS}

This was a within-subject randomized crossover trial comparing the effects of 1-day low GL meals and 1-day high GL meals, in women between 26 and 32 weeks of gestation at higher risk of GDM. Participants were recruited through the antenatal clinic at the Royal Prince Alfred Hospital, Camperdown, NSW, Australia. Women were prescreened at the time of their second obstetric appointment (19-23 weeks gestation) and invited to participate in the study. Those expressing interest were given details of the study and contacted again after routine testing for GDM at 26-28 weeks gestation. Women were eligible if they had at least one of the following risk factors for GDM: prepregnancy body mass index $(\mathrm{BMI}) \geq 30 \mathrm{~kg} / \mathrm{m}^{2}$, age $\geq 35$ years, polycystic ovarian syndrome, history of GDM or glucose intolerance, history of a previous birth $>4000 \mathrm{~g}$, family history of type 2 diabetes (first-degree relative), belonging to an ethnic group with a high prevalence of GDM (Aboriginal, Torres Strait Islander, Polynesian, Middle Eastern, South Asian, South East Asian). Women with diagnosed GDM, pre-existing diabetes, multiple pregnancy or special dietary requirements (gluten-intolerant, vegetarian) were excluded. GDM diagnosis was based on the 1998 Australian Diabetes in Pregnancy Society (ADIPS) criteria until January 2015 (fasting BGL $\geq 5.5 \mathrm{mmol} / \mathrm{L}, 1 \mathrm{~h} \mathrm{BGL} \geq 10.0 \mathrm{mmol} / \mathrm{L}$ or $2 \mathrm{~h} \mathrm{BGL}$ $\geq 8.0 \mathrm{mmol} / \mathrm{L}^{17}$ ) after which new diagnosis criteria were adopted recommending that fasting BGL $>5.1 \mathrm{mmol} / \mathrm{L}$ be classified as GDM. ${ }^{18}$ In total, 146 women were approached between January 2014 and July 2015, of whom 70 expressed interest. Of these, 39 subsequently declined, 5 were lost to follow-up, and 7 were excluded following a diagnosis of GDM (figure 1). A total of 19 women met the inclusion criteria and started the trial. This study was approved by the Human Research Ethics Committee of the Sydney South West Area Health Service (RPAH Zone). All participants gave written informed consent.

\section{Study protocol}

Continuous glucose monitors

CGM systems (Medtronic MiniMed, Northridge, California) were used to electrochemically measure

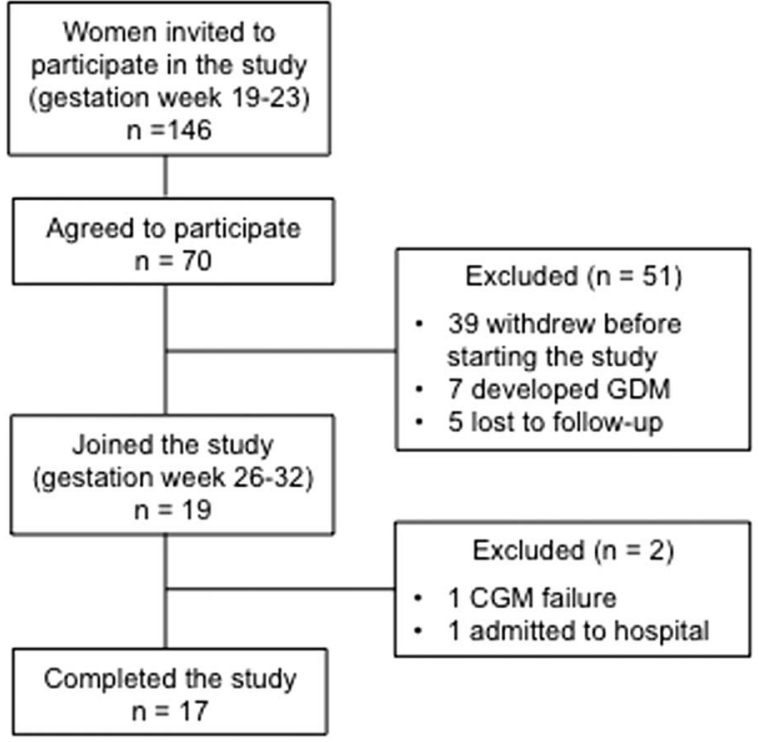

Figure 1 Participants flow diagram.

subcutaneous interstitial glucose concentrations every 5 min, generating 288 measurements per day. The monitors were calibrated four times a day against capillary blood glucose measurements, using blood glucose meters (Accu-Check Performa; Roche) as per the manufacturer's instructions. The monitors were placed on the lower back, on the right or left side, depending on the women's preference.

\section{Diet and protocol}

Women were provided with all the foods required for the 1-day low GL meals and 1-day high GL meals. Dietary macronutrient composition of the two test days were formulated by the dietitian (SB) to produce a twofold difference in GL by reducing carbohydrate content and GI, while matching the fiber content and energy (table 1). The mean GL of the high and low GL days were 144 and 70 units, over the $24 \mathrm{~h}$ period, respectively. A within-subject crossover trial was used, and the order of the low and high GL days was randomized using a computer-generated randomization program. On day 1 of CGM use, women were instructed to eat at their discretion. On days 2 and 3, women were instructed to consume the test foods provided. On day 4, the CGM was removed and data of days 2 and 3 (midnight to midnight) were extracted for analysis. Dietary compliance was assessed using the log book. Women were asked to record the time at which the meals were consumed and whether the meals were consumed entirely. In a small number of women, plate wastage was recorded.

\section{Statistical analysis}

Interstitial glucose values were obtained by CGMs. Comparison between the high and low GL days was assessed by paired Student's t-test. The mean amplitude 


\begin{tabular}{|c|c|c|c|c|c|c|c|c|c|c|c|c|c|c|c|c|c|c|c|c|c|}
\hline \multirow[b]{2}{*}{ Foods } & \multicolumn{10}{|c|}{ Low GL meal } & \multirow[b]{2}{*}{ Foods } & \multicolumn{10}{|c|}{ High GL day } \\
\hline & $\mathbf{g}$ & kJ & $\mathbf{P}$ & Fat & Sat $f$ & $\mathrm{CHO}$ & Fib & Sug & GI & GL & & $\mathbf{g}$ & kJ & $\mathbf{P}$ & Fat & Sat $f$ & $\mathrm{CHO}$ & Fib & Sug & GI & GL \\
\hline \multicolumn{11}{|l|}{ Breakfast } & \multicolumn{11}{|l|}{ Breakfast } \\
\hline $\begin{array}{l}\text { Goodness Superfoods barley } \\
\text { and oats* }\end{array}$ & 35 & 500 & 5 & 3 & 1 & 16 & 6 & 1 & 53 & 9 & Uncle Tobys High fibre oats* & 40 & 563 & 4 & 3 & 1 & 21 & 6 & 4 & 75 & 16 \\
\hline Burgen wholegrain bread & 80 & 803 & 10 & 5 & 1 & 25 & 6 & 2 & 39 & 10 & Wholemeal bread & 60 & 554 & 5 & 1 & 0 & 25 & 4 & 1 & 70 & 18 \\
\hline Vegemite spread & 20 & 117 & 5 & 0 & 0 & 2 & 0 & 0 & 0 & 0 & Vegemite spread & 20 & 117 & 5 & 0 & 0 & 2 & 0 & 0 & 0 & 0 \\
\hline \multirow[t]{2}{*}{ Margarine } & 14 & 407 & 0 & 11 & 2 & 0 & 0 & 0 & 0 & 0 & Margarine & 14 & 407 & 0 & 11 & 2 & 0 & 0 & 0 & 0 & 0 \\
\hline & & & & & & & & & & & Wheat brant & 13 & 167 & 2 & 1 & 0 & 4 & 4 & 0 & 0 & 0 \\
\hline Total $(\mathrm{g})$ & & 1827 & 20 & 19 & 4 & 43 & 12 & 3 & 45 & 18 & Total $(\mathrm{g})$ & & 1808 & 16 & 16 & 3 & 52 & 14 & 4 & 67 & 34 \\
\hline \multicolumn{11}{|l|}{ Lunch } & \multicolumn{11}{|l|}{ Lunch } \\
\hline Burgen wholegrain bread & 80 & 803 & 10 & 5 & 1 & 25 & 6 & 2 & 39 & 10 & Wholemeal bread & 90 & 866 & 8 & 2 & 0 & 38 & 6 & 2 & 70 & 26 \\
\hline Tuna canned in oil & 80 & 559 & 22 & 5 & 1 & 0 & 0 & 0 & 0 & 0 & Tuna canned in oil & 80 & 559 & 22 & 5 & 1 & 0 & 0 & 0 & 0 & 0 \\
\hline Tomato (1 average) & 80 & 40 & 0 & 0 & 0 & 2 & 1 & 0 & 0 & 0 & Tomato (1 average) & 80 & 40 & 0 & 0 & 0 & 2 & 1 & 0 & 0 & 0 \\
\hline Cucumber (1 average) & 100 & 40 & 0 & 0 & 0 & 2 & 1 & 0 & 0 & 0 & Cucumber (1 average) & 100 & 40 & 0 & 0 & 0 & 2 & 1 & 0 & 0 & 0 \\
\hline Lettuce (1 cup) & 35 & 8 & 0 & 0 & 0 & 0 & 1 & 0 & 0 & 0 & Lettuce (1 cup) & 35 & 8 & 0 & 0 & 0 & 0 & 1 & 0 & 0 & 0 \\
\hline Dressing (ready) & 30 & 265 & 0 & 5 & 1 & 5 & 0 & 4 & 0 & 0 & Dressing (ready) & 30 & 265 & 0 & 5 & 1 & 5 & 0 & 4 & 0 & 0 \\
\hline Be Natural nut bar & 40 & 870 & 8 & 15 & 2 & 12 & 3 & 8 & 29 & 3 & Vita-weat biscuits & 30 & 453 & 3 & 2 & 0 & 19 & 3 & 1 & 65 & 12 \\
\hline Total $(\mathrm{g})$ & & 2585 & 40 & 30 & 5 & 46 & 12 & 2 & 32 & 13 & Total $(\mathrm{g})$ & & 2231 & 33 & 14 & 2 & 66 & 12 & 7 & 64 & 39 \\
\hline \multicolumn{11}{|l|}{ Afternoon tea } & \multicolumn{11}{|l|}{ Afternoon tea } \\
\hline \multirow[t]{3}{*}{ Activia yogurt } & 125 & 448 & 6 & 2 & 1 & 17 & 0 & 16 & 25 & 4 & Sakata rice crackers & 30 & 471 & 2 & 1 & 0 & 25 & 0 & 1 & 80 & 20 \\
\hline & & & & & & & & & & & Carrot (1 average) & 70 & 80 & 0 & 0 & 0 & 4 & 2 & 0 & 16 & 1 \\
\hline & & & & & & & & & & & Philadelphia cream cheese & 40 & 305 & 3 & 6 & 4 & 2 & 0 & 0 & 0 & 0 \\
\hline Total $(\mathrm{g})$ & & 448 & 6 & 2 & 1 & 17 & 0 & 16 & 25 & 4 & Total $(\mathrm{g})$ & & 856 & 5 & 7 & 4 & 31 & 2 & 1 & 67 & 21 \\
\hline \multicolumn{11}{|l|}{ Dinner } & \multicolumn{11}{|l|}{ Dinner } \\
\hline Edgell four bean mix & 75 & 379 & 6 & 1 & 0 & 12 & 6 & 2 & 37 & 5 & Mashed potato (dry)‡ & 25 & 420 & 2 & 2 & 1 & 18 & 3 & 2 & 85 & 16 \\
\hline Inghams chicken breast & 100 & 858 & 13 & 9 & 2 & 19 & 0 & 3 & 0 & 0 & Inghams chicken breast & 100 & 858 & 13 & 9 & 2 & 19 & 0 & 3 & 0 & 0 \\
\hline Tomatoes (2 average) & 160 & 80 & 0 & 0 & 0 & 4 & 2 & 0 & 0 & 0 & Tomatoes (2 average) & 160 & 80 & 0 & 0 & 0 & 4 & 2 & 0 & 0 & 0 \\
\hline Cucumber (1 average) & 100 & 40 & 0 & 0 & 0 & 2 & 1 & 0 & 0 & 0 & Cucumber (1 average) & 100 & 40 & 0 & 0 & 0 & 2 & 0 & 0 & 0 & 0 \\
\hline Lettuce (1 cup) & 35 & 8 & 0 & 0 & 0 & 0 & 1 & 0 & 0 & 0 & Lettuce (1 cup) & 35 & 8 & 0 & 0 & 0 & 0 & 1 & 0 & 0 & 0 \\
\hline Sweet corn canned & 72 & 231 & 2 & 1 & 0 & 9 & 2 & 1 & 55 & 5 & Sweet corn canned & 72 & 231 & 2 & 1 & 0 & 9 & 2 & 1 & 55 & 5 \\
\hline \multirow[t]{2}{*}{ Dressing (ready) } & 30 & 265 & 0 & 5 & 1 & 5 & 0 & 4 & 0 & 0 & Dressing (ready) & 30 & 265 & 0 & 5 & 1 & 5 & 0 & 4 & 0 & 0 \\
\hline & & & & & & & & & & & Wheat bran $\S$ & 6 & 48 & 0 & 0 & 0 & 2 & 2 & 0 & 0 & 0 \\
\hline Total $(\mathrm{g})$ & & 1861 & 21 & 16 & 3 & 51 & 12 & 10 & 41 & 19 & Total $(\mathrm{g})$ & & 1950 & 17 & 17 & 4 & 59 & 10 & 10 & 56 & 30 \\
\hline \multicolumn{11}{|l|}{ Supper } & \multicolumn{11}{|l|}{ Supper } \\
\hline Belvita biscuits & 50 & 964 & 4 & 8 & 1 & 36 & 3 & 11 & 45 & 16 & SunRice rice cakes & 40 & 663 & 3 & 4 & 1 & 28 & 2 & 0 & 78 & 22 \\
\hline Total $(\mathrm{g})$ & & 964 & 4 & 8 & 1 & 36 & 3 & 11 & 45 & 16 & Total (g) & & 663 & 3 & 4 & 1 & 28 & 2 & 0 & 78 & 22 \\
\hline Total (g) & & 7685 & 91 & 74 & 14 & 193 & 39 & 54 & 39 & 70 & Total (g) & & 7508 & 74 & 58 & 14 & 236 & 41 & 23 & 65 & 144 \\
\hline Total \% energy & & & 20 & 36 & 7 & 40 & 4 & 11 & & & Total \% energy & & & 17 & 29 & 7 & 50 & 4 & 5 & & \\
\hline \multicolumn{22}{|c|}{ Total \% energy does not account for the energy provided by fiber $(2 \mathrm{kcal} / \mathrm{g})$. } \\
\hline
\end{tabular}


of glycemic excursion (MAGE) was determined by calculating the arithmetic mean of the difference between consecutive peaks and nadirs if the difference was $>1$ SD of the mean glucose, ${ }^{19}{ }^{20}$ using the automated GlyCulator algorithm. ${ }^{21}$ The incremental area under the curve (iAUC) was calculated across the $24 \mathrm{~h}$, using the trapezoidal rule. The glucose value at midnight was used as baseline, and all the interstitial glucose output from the CGMs were used. Any area below baseline concentration was ignored. All the other variables were generated by transferring the CGM stored data into the data management system. The sample size calculation was based on the mean \pm SEM of iAUC glucose reported by Solomon $e t a l^{22}$ in eight participants consuming representative diets (low GI or high GI) over the course of the day. In our study, a sample of 12 participants provided $>80 \%$ power to detect a difference greater than twofold between the high and low GL groups, with an $\alpha$-value of 0.05 .

\section{RESULTS}

In total, 19 women started the trial. Data were not recorded for one participant because of CGM failure. One participant was admitted to hospital on day 2 for reasons unrelated to the study, and her data were excluded from the analysis. Results were available for the remaining 17 participants, including two full 24 hours (midnight to midnight) glucose monitoring days.
Dietary compliance was higher on the low GL day compared to the high GL day. On the low GL day, one woman did not consume the supper $(\sim 960 \mathrm{~kJ}$ deficit). On the high GL day, two women did not consume the supper ( $\sim 660 \mathrm{~kJ}$ deficit), two ate half of the supper ( $\sim 330 \mathrm{~kJ}$ deficit), one ate half of the afternoon tea ( $\sim 420 \mathrm{~kJ}$ deficit) and one ate half of the breakfast porridge $(\sim 280 \mathrm{~kJ}$ deficit$)$. The omission of these foods resulted in a reduction in the daily total energy content of between $4 \%$ and $12 \%$. The mean \pm SD age was 34.8 \pm 4 years and prepregnancy BMI was $23.8 \pm 4.7 \mathrm{~kg} / \mathrm{m}^{2}$. The mean gestational age at study entry was 29.3 \pm 1.3 weeks, and $71 \%$ of the participants were Caucasian.

\section{Dietary GL and diurnal glucose levels}

Diurnal glucose responses measured by CGMs on the high GL day and low GL day are shown in figure 2, and summary results are presented in table 2 .

Diurnal glucose levels were significantly lower on the low GL day, as demonstrated by a $51 \%$ lower iAUC on the low GL day compared to the high GL day (iAUC ${ }_{ \pm} \mathrm{SEM} 549 \pm 109 \mathrm{mmol} / \mathrm{L} \mathrm{min}$ vs $1120 \pm 198 \mathrm{mmol} / \mathrm{L} \mathrm{min}$, $\mathrm{p}=0.015$ ). The peak glucose concentration was also significantly lower on the low GL day $($ mean \pm SEM 7.1 $\pm 0.2 \mathrm{mmol} / \mathrm{L}$ vs $7.6 \pm 0.2 \mathrm{mmol} / \mathrm{L}, \mathrm{p}=0.026$ ). Time spent within the normal (target) glucose range was significantly longer on the low GL day, resulting from fewer above and lesser below target values, hence

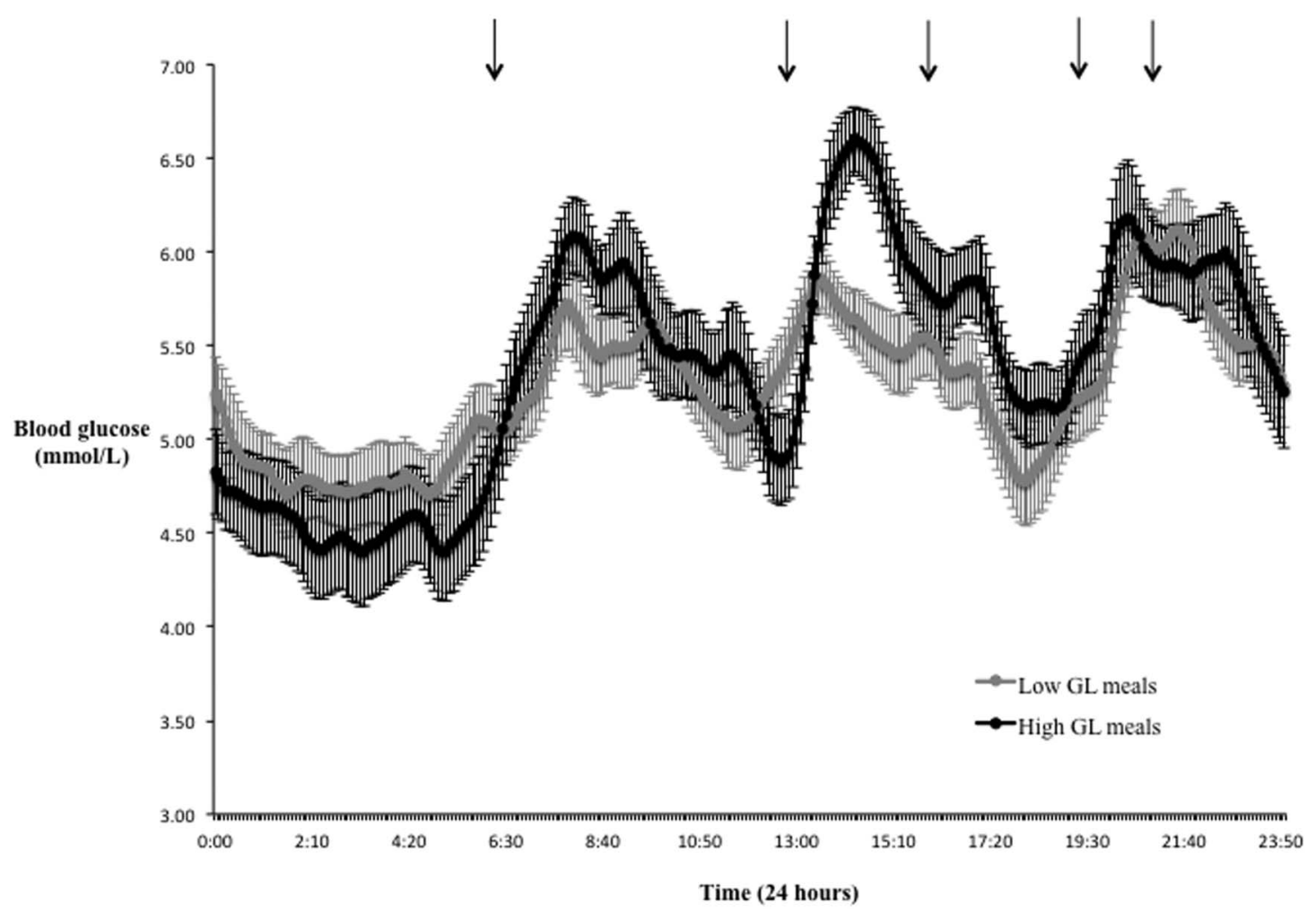

Figure 2 Mean ( \pm SEM) diurnal glucose levels following low GL meals (gray dots) and high GL meals (black dots). Average mealtimes are represented by the black arrows. 
Table 2 Average maternal glucose levels $(n=17)$ for the low GL and high GL meals

\begin{tabular}{lrrr}
\hline & Low GL & High GL & p Value \\
\hline $\begin{array}{l}\text { Highest glucose value } \\
\text { (mmol/L) }\end{array}$ & $7.1 \pm 0.2$ & $7.6 \pm 0.2$ & 0.026 \\
$\begin{array}{l}\text { Lowest glucose value } \\
\text { (mmol/L) }\end{array}$ & $3.9 \pm 0.2$ & $3.7 \pm 0.2$ & 0.237 \\
Average (mmol/L) & $5.3 \pm 0.1$ & $5.4 \pm 0.2$ & 0.352 \\
SD average (mmol/L) & $0.7 \pm 0.1$ & $0.9 \pm 0.1$ & $<0.001$ \\
MAGE (mmol/L) & $2.1 \pm 0.2$ & $2.7 \pm 0.2$ & $<0.001$ \\
iAUC (mmol/L min) & $549 \pm 109$ & $1120 \pm 198$ & 0.015 \\
Proportion of time (\%) & & & \\
$\quad$ In target (3.9-7.8 & $95.1 \pm 1.7$ & $87.7 \pm 3.2$ & 0.031 \\
$\quad$ mmol/L) & & & \\
$\quad \begin{array}{l}\text { Above target } \\
\text { Below target }\end{array}$ & $0.4 \pm 0.2$ & $4.4 \pm 2.8$ & 0.180 \\
\hline
\end{tabular}

Mean \pm SEM (all such values).

iAUC, incremental area under the curve (calculated across the $24 \mathrm{~h}$, using the trapezoidal rule); MAGE, mean amplitude of glycemic excursions (determined by calculating the arithmetic mean of the difference between consecutive peaks and nadirs if the difference is $>1 \mathrm{SD}$ of the mean glucose).

demonstrating less glucose oscillation (low GL 95.1 $\pm 1.7 \%$ vs high GL $87.7 \pm 3.2 \%, \mathrm{p}=0.031$ ).

Glycemic variability was significantly lower on the low GL day, as demonstrated by a lower average SD and lower MAGE (SD average $0.7 \pm 0.1$ vs $0.9 \pm 0.1, \mathrm{p}<0.001$; MAGE $2.1 \pm 0.2 \mathrm{mmol} / \mathrm{L}$ vs $2.7 \pm 0.2 \mathrm{mmol} / \mathrm{L}, \mathrm{p}<0.001)$.

\section{CONCLUSIONS}

To the best of our knowledge, this is the first study to explore the effects of modestly higher protein/lower carbohydrate (lower GL) meals versus conventional meals on day-long glucose profiles in women at risk of GDM. Our findings show that the low GL diet achieved improved glycemic control as judged by $\sim 50 \%$ lower diurnal glucose levels, increased time within target glucose range and less glycemic oscillation than the conventional diet. Our findings have implications for improving the dietary management of pregnant women with overweight, obesity, and other risk factors for GDM.

Increased maternal glycemia is associated with excessive growth and adiposity, ${ }^{123}$ poor vascular health, ${ }^{24}$ and increased risk of metabolic disorders and obesity in the offspring. ${ }^{10}{ }^{25}$ Higher glycemic variability, even of a modest degree, has been linked to higher fetal ponderal index, independently of glycated haemoglobin, in pregnant women with type 1 diabetes. ${ }^{5}$ In the present study, MAGE and average SD were significantly lower on the low GL day, potentially reducing the risk of preeclampsia and neonatal complications associated with high MAGE. ${ }^{26}$

Currently, diet therapy aimed at lowering BGLs represents the first line of treatment in women with GDM. ${ }^{27}$ In a previous study, we demonstrated that a low GI diet reduced the need for insulin therapy, without increasing the risk of adverse pregnancy outcomes. ${ }^{28}$ In a self- selected subgroup of pregnant women at high risk of GDM, a low GI diet resulted in improved infant weight-for-age and length-for-age z-scores and thinner carotid intima-media thickness at 1 year of age. ${ }^{24}$ In women with a history of macrosomia, a low GI diet improved glucose tolerance and gestational weight gain, although not the risk of macrosomia. ${ }^{29}$

In this study, improvement in maternal glucose levels on the low GL diet was achieved by reducing the proportion of energy as carbohydrate (from $50 \%$ to $40 \% \mathrm{E}$ ), as well as by replacing high GI sources of carbohydrate with low GI sources. The reduction in carbohydrate energy was accompanied by a modest increase in protein energy (from $17 \%$ to $20 \% \mathrm{E}$ ) and fat energy (from $29 \%$ to $36 \% \mathrm{E}$ ). However, the meals with the largest difference in GL (lunch and afternoon tea) produced the largest difference in postprandial glycemia over the course of the day. Thus, carbohydrate and GI influence ambient glucose concentrations. Importantly, the sources of fat were chosen such that there was no increase in the proportion of energy as saturated fat $(<10 \%$ in both diets). The low GL diet therefore resembled a modestly lower carbohydrate diet, similar to that associated with the lowest risk of metabolic syndrome in the PREDIMED study. ${ }^{30}$ A recent meta-analysis indicates that this macronutrient distribution is associated with better markers of glucose homeostasis and HbA1c than higher carbohydrate diets. ${ }^{31}$

Our findings should not be interpreted as a 'green light' for low or very low carbohydrate diets in women at risk of GDM. Severe restriction of carbohydrate markedly increases fatty acid oxidation and therefore ketone levels. $^{32}$ In pregnancy, the risks associated with high maternal ketone concentration are currently unclear but may include adverse effects on offspring intelligence. ${ }^{33}$ Furthermore, carbohydrate-restricted diets may induce unbalanced macronutrient intake by increasing dietary fat. ${ }^{34}$ Data in pregnancy suggest a strong influence of maternal triglycerides and free-fatty acids (FFAs) on excessive fetal adiposity accretion. ${ }^{35}{ }^{36}$ However, in GDM, diets with lower fat and higher 'complex' carbohydrate resulted in lower levels of maternal fasting glucose and FFAs, compared to a conventional diet. ${ }^{37}$ Outside of pregnancy, high fat diets have been shown to promote insulin resistance. $^{38}$

The strengths of this study include the randomized controlled design, the use of CGM with frequent assessment of maternal glucose concentrations across the day and the provision of foods with known (tested) GI and nutrient composition and the crossover study design. To best represent typical lifestyle patterns within the study, participants were free-living and the meals were consumed according to the mother's schedule. Our study had some limitations, most notably the small sample size and the short duration of the study; only $24 \mathrm{~h}$ per GL diet of CGM data were analyzed instead of an average over $>1$ day which might not represent the true day-to-day variation in glycemic response. Only acute 
effects were reported, and there was no lead in diets and no washout day. More tightly controlled meal times may have increased the differences between the two diets.

In conclusion, this study showed that, in third trimester pregnant women at risk of GDM, low GL meals improve diurnal glycemic control and glycemic variability, compared to high GL meals. This study adds to the evidence supporting the utility of a low GL diet in pregnancy to optimize glycemic control.

\section{Author affiliations}

${ }^{1}$ Charles Perkins Centre, The University of Sydney, Sydney, New South Wales, Australia

${ }^{2}$ School of Life and Environmental Sciences, The University of Sydney, Sydney, New South Wales, Australia

${ }^{3}$ IEL-Nutritional Epidemiology, University of Bonn, DONALD Study, Dortmund, Germany

${ }^{4}$ Boden Institute of Obesity, Nutrition, Exercise \& Eating Disorders, The University of Sydney, Sydney, New South Wales, Australia

${ }^{5}$ Department of Endocrinology, Royal Prince Alfred Hospital, Camperdown, New South Wales, Australia

${ }^{6}$ Sydney Medical School, The University of Sydney, Sydney, New South Wales, Australia

Acknowledgements The authors thank all the study participants.

Contributors JPB-M, NVK, AB, JG, GPR, and TPM conceived and designed the study; NVK and JG researched the data; NVK analyzed the data and wrote the manuscript; SB designed the diets; and FSA was involved in the design of the diets and generated the incremental area under the curve. All authors reviewed and approved the final manuscript. JPB-M is the guarantor of this work and takes responsibility for the contents of the article.

Competing interests JPB-M is the President of the Glycemic Index Foundation, Director of the Sydney University Glycemic Index Research Service and author of popular books about the glycemic index of foods. FSA is a director of the Glycemic Index Foundation, manages the Sydney University Glycemic Index Research Service and is a coauthor of popular books about the glycemic index of foods. No other potential conflicts of interest relevant to this article are declared.

Ethics approval Sydney South West Area Health Service (RPAH Zone). Provenance and peer review Not commissioned; externally peer reviewed. Data sharing statement No additional data are available.

Open Access This is an Open Access article distributed in accordance with the Creative Commons Attribution Non Commercial (CC BY-NC 4.0) license, which permits others to distribute, remix, adapt, build upon this work noncommercially, and license their derivative works on different terms, provided the original work is properly cited and the use is non-commercial. See: http:// creativecommons.org/licenses/by-nc/4.0/

\section{REFERENCES}

1. Metzger BE, Lowe LP, Dyer AR, et al. Hyperglycemia and adverse pregnancy outcomes. N Engl J Med 2008;358:1991-2002.

2. Crume TL, Ogden L, Daniels S, et al. The impact of in utero exposure to diabetes on childhood body mass index growth trajectories: the EPOCH Study. J Pediatrics 2011;158:941-6.

3. Catalano PM. The impact of gestational diabetes and maternal obesity on the mother and her offspring. J Dev Orig Health Dis 2010;1:208-15.

4. Hillier TA, Pedula KL, Schmidt MM, et al. Childhood obesity and metabolic imprinting: the ongoing effects of maternal hyperglycemia. Diabetes Care 2007;30:2287-92.

5. Dalfra MG, Sartore G, Di Cianni G, et al. Glucose variability in diabetic pregnancy. Diabetes Technol Ther 2011;13:853-9.

6. Su JB, Wang XQ, Chen JF, et al. Glycemic variability in gestational diabetes mellitus and its association with beta cell function. Endocrine 2013;43:370-5.
7. Chang CM, Hsieh CJ, Huang JC, et al. Acute and chronic fluctuations in blood glucose levels can increase oxidative stress in type 2 diabetes mellitus. Acta Diabetol 2012;49(Suppl 1): S171-7.

8. Monnier L, Mas E, Ginet C, et al. Activation of oxidative stress by acute glucose fluctuations compared with sustained chronic hyperglycemia in patients with type 2 diabetes. JAMA 2006;295:1681-7.

9. Ceriello A, Esposito K, Piconi L, et al. Oscillating glucose is more deleterious to endothelial function and oxidative stress than mean glucose in normal and type 2 diabetic patients. Diabetes 2008;57:1349-54

10. Dabelea D, Crume T. Maternal environment and the transgenerational cycle of obesity and diabetes. Diabetes 2011;60:1849-55.

11. Brand-Miller JC, Stockmann K, Atkinson F, et al. Glycemic index postprandial glycemia, and the shape of the curve in healthy subjects: analysis of a database of more than 1,000 foods. Am J Clin Nutr 2009;89:97-105.

12. Brynes AE, Adamson J, Dornhorst A, et al. The beneficial effect of a diet with low glycaemic index on $24 \mathrm{~h}$ glucose profiles in healthy young people as assessed by continuous glucose monitoring. Br J Nutr 2005;93:179-82.

13. Nansel TR, Gellar L, McGill A. Effect of varying glycemic index meals on blood glucose control assessed with continuous glucose monitoring in youth with type 1 diabetes on basal-bolus insulin regimens. Diabetes Care 2008;31:695-7.

14. Brynes AE, Lee JL, Brighton RE, et al. A low glycemic diet significantly improves the 24-h blood glucose profile in people with type 2 diabetes, as assessed using the continuous glucose MiniMed monitor. Diabetes Care 2003;26:548-9.

15. Fabricatore AN, Ebbeling CB, Wadden TA, et al. Continuous glucose monitoring to assess the ecologic validity of dietary glycemic index and glycemic load. Am J Clin Nutr 2011;94:1519-24.

16. Bao J, Atkinson F, Petocz $\mathrm{P}$, et al. Prediction of postprandial glycemia and insulinemia in lean, young, healthy adults: glycemic load compared with carbohydrate content alone. Am J Clin Nutr 2011;93:984-96.

17. Hoffman L, Nolan C, Wilson JD, et al. Gestational diabetes mellitus -management guidelines. The Australasian Diabetes in Pregnancy Society. Med J Aust 1998;169:93-7.

18. Metzger BE, Gabbe SG, Persson B, et al., International Association of Diabetes and Pregnancy Study Groups Consensus Panel. International association of diabetes and pregnancy study groups recommendations on the diagnosis and classification of hyperglycemia in pregnancy. Diabetes Care 2010;33:676-82.

19. Service FJ. Glucose variability. Diabetes 2013;62:1398-404.

20. Baghurst PA. Calculating the mean amplitude of glycemic excursion from continuous glucose monitoring data: an automated algorithm. Diabetes Technol Ther 2011;13:296-302.

21. Czerwoniuk D, Fendler W, Walenciak L, et al. GlyCulator: a glycemic variability calculation tool for continuous glucose monitoring data. J Diabetes Sci Technol 2011;5:447-51.

22. Solomon TP, Haus JM, Kelly KR, et al. A low-glycemic index diet combined with exercise reduces insulin resistance, postprandial hyperinsulinemia, and glucose-dependent insulinotropic polypeptide responses in obese, prediabetic humans. Am J Clin Nutr 2010;92:1359-68.

23. HAPO Study Cooperative Research Group. Hyperglycemia and Adverse Pregnancy Outcome (HAPO) Study: associations with neonatal anthropometrics. Diabetes 2009;58:453-9.

24. Kizirian NV, Kong Y, Muirhead R, et al. Effects of a low-glycemic index diet during pregnancy on offspring growth, body composition, and vascular health: a pilot randomized controlled trial. Am J Clin Nutr 2016;103:1073-82.

25. Ma RC, Tutino GE, Lillycrop KA, et al. Maternal diabetes, gestational diabetes and the role of epigenetics in their long term effects on offspring. Prog Biophys Mol Biol 2015;118:55-68.

26. Yu F, Lv L, Liang Z, et al. Continuous glucose monitoring effects on maternal glycemic control and pregnancy outcomes in patients with gestational diabetes mellitus: a prospective cohort study. J Clin Endocrinol Metab 2014;99:4674-82.

27. Blumer I, Hadar E, Hadden DR, et al. Diabetes and pregnancy: an endocrine society clinical practice guideline. J Clin Endocrinol Metab 2013;98:4227-49.

28. Moses RG, Barker M, Winter M, et al. Can a low-glycemic index diet reduce the need for insulin in gestational diabetes mellitus? A randomized trial. Diabetes Care 2009;32:996-1000.

29. Walsh JM, McGowan CA, Mahony R, et al. Low glycaemic index diet in pregnancy to prevent macrosomia (ROLO study): randomised control trial. BMJ 2012;345:e5605.

30. Juanola-Falgarona M, Salas-Salvado J, Buil-Cosiales P, et al. Dietary glycemic index and glycemic load are positively associated 
with risk of developing metabolic syndrome in middle-aged and elderly adults. J Am Geriatr Soc 2015;63:1991-2000.

31. Imamura F, Micha R, Wu JH, et al. Effects of saturated fat, polyunsaturated fat, monounsaturated fat, and carbohydrate on glucose-insulin homeostasis: a systematic review and meta-analysis of randomised controlled feeding trials. PLoS Med 2016;13:e1002087.

32. Cotter DG, Schugar RC, Crawford PA. Ketone body metabolism and cardiovascular disease. Am J Physiol Heart Circ Physiol 2013;304: $\mathrm{H} 1060-76$.

33. Rizzo T, Metzger BE, Burns WJ, et al. Correlations between antepartum maternal metabolism and child intelligence. $N$ Engl J Med 1991;325:911-6.

34. Hernandez TL. Carbohydrate content in the GDM Diet: two views: view 1: nutrition therapy in gestational diabetes: the case for complex carbohydrates. Diabetes Spectr 2016;29:82-8.
35. Harmon KA, Gerard L, Jensen DR, et al. Continuous glucose profiles in obese and normal-weight pregnant women on a controlled diet: metabolic determinants of fetal growth. Diabetes Care 2011;34:2198-204.

36. Schaefer-Graf UM, Graf K, Kulbacka I, et al. Maternal lipids as strong determinants of fetal environment and growth in pregnancies with gestational diabetes mellitus. Diabetes Care 2008;31:1858-63.

37. Hernandez TL, Van Pelt RE, Anderson MA, et al. Women with gestational diabetes randomized to a higher-complex carbohydrate/ low-fat diet manifest lower adipose tissue insulin resistance, inflammation, glucose, and free fatty acids: a pilot study. Diabetes Care 2016;39:39-42.

38. Lichtenstein AH, Schwab US. Relationship of dietary fat to glucose metabolism. Atherosclerosis 2000;150:227-43. 